\title{
Transforming growth factor- $\beta 2$ antibody attenuates fibrosis in the experimental diabetic rat kidney
}

\author{
C Hill ${ }^{1}$, A Flyvbjerg, R Rasch, M Bak and A Logan ${ }^{1}$ \\ Institute of Clinical Research, University of Aarhus, Aarhus, DK-8000, Denmark \\ ${ }^{1}$ Department of Medicine, University of Birmingham, Edgbaston, Birmingham B15 2TH, UK \\ (Requests for offprints should be addressed to A Logan, Department of Medicine, University of Birmingham, Wolfson Research Laboratories, \\ Queen Elizabeth Medical Centre, Edgbaston, Birmingham B15 2TH, UK; Email: a.logan@bham.ac.uk)
}

\begin{abstract}
Diabetic nephropathy is characterised by an increase in glomerular and tubular fibrosis that compromises kidney function. The transforming growth factor- $\beta$ s (TGF- $\beta \mathrm{s}$ ) have been shown to play a major role in fibrosis and we have shown that TGF- $\beta 2$, in particular, increases coordinately with fibrogenesis in the diabetic kidney. The aim of this study was to investigate the changes in expression of extracellular matrix molecules in the diabetic kidney, with and without systemic administration of a recombinant human monoclonal antibody to TGF- $\beta 2$. Streptozotocin-induced diabetic rats were split into two groups. The first were treated with $5 \mathrm{mg} / \mathrm{kg}$ irrelevant control IgG4 (placebo) and the second treated with $5 \mathrm{mg} / \mathrm{kg}$ isoform-specific recombinant monoclonal antiTGF- $\beta 2$ IgG4 (termed CAT-152) systemically every second day for 14 days. A further group of six non-diabetic rats was also used as a control. Various biological parameters were measured daily throughout the experimental period, and on termination of the experiment at 14 days Western blotting was performed on kidney cortices for procollagen-I C-propeptide, which is an indicator of the rate of collagen-I synthesis within the kidney.
\end{abstract}

In the placebo-treated diabetic rats, blood glucose, food consumption, urinary albumin excretion (UAE) and kidney weights were all significantly higher than in the non-diabetic group $(P<0 \cdot 05, n=24$, by ANOVA). In the anti-TGF- $\beta 2$-treated diabetic rats, kidney weights and UAE levels were decreased when compared with those in placebo-treated diabetics. Western blotting for the procollagen-I C-propeptide in kidney cortices showed a significant increase in levels in placebo-treated diabetic rats compared with non-diabetic controls over the 14 day diabetic period, indicating initiation of fibrogenesis. By contrast, in anti-TGF- $\beta 2$-treated diabetic rats, levels of the propeptide remained at non-diabetic levels.

In summary, a significant suppression of kidney fibrosis was seen in anti-TGF- $\beta 2$-treated diabetic rats, compared with placebo-treated diabetic rats. We conclude that systemic delivery of CAT-152, a neutralising antiTGF- $\beta 2$ antibody, during the acute stages of diabetic nephropathy reduces the rate of pathogenic fibrosis in the kidney.

Journal of Endocrinology (2001) 170, 647-651

\section{Introduction}

The fibrogenic transforming growth factor- $\beta$ (TGF- $\beta$ ) system (Rocco et al. 1992, Ziyadeh et al. 1992, Pankewycz et al. 1994, Shankland \& Scholey1994, Sharma \& Ziyadeh 1994, Hill et al. 2000) has, in addition to several other growth factor systems (Flyvbjerg 1997, Flyvbjerg et al. 1999), been suggested to play a role in the development of diabetic nephropathy. Diabetic nephropathy accounts for approximately $30 \%$ of all new cases of end stage renal failure, making it one of the major causes of end stage renal failure in the Western world (Deckert et al. 1978, Viberty et al. 1982, Mogensen \& Christensen 1984, Borch-Johnsen \& Kreiner 1987). Early changes in incipient diabetic kidney disease include an increase in kidney size, glomerular volume and kidney function and accumu- lation of glomerular extracellular matrix, increased urinary albumin excretion (UAE), glomerular sclerosis and tubular fibrosis (Osterby et al. 1967, Seyer-Hansen 1976, Flyvbjerg et al. 1992, Park et al. 1997) Previous studies have shown the importance of the TGF- $\beta$ axis and suggested its link with fibrosis in the early stages of diabetic nephropathy (Rocco et al. 1992, Shankland \& Scholey 1994, Hill et al. 2000).

Studies have shown that a pan-neutralising anti-TGF- $\beta$ antibody administered in vivo to mice with streptozotocin (STZ)-induced diabetes for 9 days attenuated elevated renal TGF- $\beta 1$ and TGF- $\beta$ receptor II mRNA levels and reduced both the diabetes-associated renal/glomerular growth and enhanced renal expression of collagen-IV and fibronectin (Sharma et al. 1996). Previous studies by a different group have used a pan-neutralising TGF- $\beta$ 
monoclonal antibody on $d b / d b$ diabetic mice which prevented a decrease in kidney function seen in type II diabetes (Ziyadeh et al. 2000). Also, Border et al. (1990) administered an anti-TGF- $\beta 1$ antibody at the time of induction of the glomerular disease, glomerulonephritis, which suppressed the increased production of extracellular matrix and dramatically attenuated histological manifestations of the disease. The impressive suppression of the experimental disease achieved with the anti-TGF- $\beta$ treatment demonstrates the importance of TGF- $\beta$ in regulating extracellular matrix production in glomerulonephritis.

Previous work by our group (Hill et al. 2000) has demonstrated that levels of the TGF- $\beta 2$ isoform rose rapidly in glomeruli and tubules during the acute phase of experimental diabetes (day 3-14) when the rate of synthesis of collagen-I, an extracellular matrix protein, increased maximally in rat kidney cortex. The relative contribution of the TGF- $\beta 2$ isoform to fibrogenesis in the diabetic kidney is unknown. The study described here shows that systemic delivery of a specific TGF- $\beta 2$ neutralising antibody, CAT-152, in vivo during the acute pre-fibrotic stages of diabetic nephropathy significantly attenuates the rate of collagen-I synthesis and reduces UAE levels in diabetic rat kidneys. This indicates the fibrogenic activity of the TGF- $\beta 2$ isoform in the diabetic kidney and the potential for related antagonists in renoprotection in this disease.

\section{Materials and Methods}

\section{Antibodies}

The antagonist used to block TGF- $\beta 2$ activity was a recombinant human monoclonal antibody, which was a gift from Cambridge Antibody Technology Ltd, Melbourn, Cambs, UK. The antibody, termed CAT-152, was a recombinant IgG4 antibody with a fully human sequence, directed against TGF- $\beta 2$. The $\mathrm{VH}$ and VL variable regions of CAT-152 were obtained by selection on active human TGF- $\beta 2$ from phage display libraries of human single chain Fv antibody molecules (Jackson et al. 1998). A whole antibody molecule of the IgG4 isotype was then constructed by recombinant techniques and expressed in NSO myeloma cells and purified. The recombinant antibody, originally termed 6B1, but now named CAT-152, has been well characterised (Thompson et al. 1999). For example, it (i) has a high affinity for TGF- $\beta 2$ with a dissociation constant of $0.89 \mathrm{nM}$, as determined by binding to TGF- $\beta 2$ using the BIACore biosensor (BIACore International AB, Uppsala, Sweden); (ii) shows approximately $9 \%$ cross-reactivity with TGF- $\beta 3$ (dissociation constant $10 \mathrm{nM}$ ) compared with TGF- $\beta 2$; (iii) has no detected binding to TGF- $\beta 1$; (iv) is specific for the active form of TGF- $\beta 2$ and does not significantly bind the latent form; (v) strongly neutralises the antiproliferative effect of TGF- $\beta 2$ in bioassays using
TF1 human erythroleukaemia cells with an $\mathrm{IC}_{50}$ of $1-2 \mathrm{nM}$; (vi) has strong inhibition of binding of TGF- $\beta 2$ to cell surface receptors in a radioreceptor assay using A549 cells; (vii) has some ability to neutralise and inhibit TGF- $\beta 3$ binding, as would be expected from the $9 \%$ cross-reactivity; (viii) has no significant ability to inhibit or neutralise TGF- $\beta 1$ binding as would be expected from the non-detected binding by BIACore; (ix) shows no detected cross-reactivity with related or unrelated antigens by immunocytochemistry and ELISA; and (x) binds to active TGF- $\beta 2$ from human, rat, mouse, pig and rabbit. Hence, it was appropriate for use as a high-affinity, isoformspecific neutralising antibody for rat TGF- $\beta 2$ in the rat model employed in this study. An irrelevant IgG4 was used as the control immunoglobulin in the placebo-treated group.

The antibody against procollagen-I C-propeptide was a gift from AstraZeneca plc (Macclesfield, Cheshire, UK) and was used for Western blotting at a dilution of 1:10 000 .

\section{Animals}

Thirty female Wistar rats (Mollegaards Avlslab, Eiby, Denmark) aged 65 days, weighing approximately $180 \mathrm{~g}$ were used in this protocol. All animals had an i.v. catheter surgically inserted into the jugular vein. Once recovered from the operation (3-4 days), 24 rats received $50 \mathrm{mg} / \mathrm{kg}$ body weight of STZ via the i.v. catheter on day 0 of the experiment, the other six acted as untreated non-diabetic controls. Twelve diabetic rats were given $5 \mathrm{mg} / \mathrm{kg}$ body weight of the anti-TGF- $\beta 2$ antibody CAT- 152 every second day. Twelve diabetic rats and six non-diabetic rats were given $5 \mathrm{mg} / \mathrm{kg}$ placebo (an irrelevant IgG4 control immunoglobulin) every second day and acted as placebotreated controls. Body weight, blood glucose, food consumption and UAE were recorded daily throughout the experimental period. The experiment was terminated at day 14 when the kidneys were removed, weighed and dissected to separate the cortices. The left kidney cortices were snap-frozen for later Western blotting and the right cortices were processed for measurement of glomerular volume as described below. For this part of the study, animal procedures and care were consistent with the licences held by Aarhus University, Denmark, which fulfil and follow international rules and guidelines.

\section{$U A E$}

The urinary albumin concentration in $24 \mathrm{~h}$ urine collections was determined by RIA as previously described (Flyvbjerg et al. 1992) using rat albumin antibody and standards. The urine samples were stored at $-20{ }^{\circ} \mathrm{C}$ until the assay was performed. Rabbit anti-rat albumin antibody RARa/Alb was purchased from Nordic Pharmaceuticals and Diagnostics (Tilburg, Netherlands). For standard and iodination a globulin-free rat albumin was obtained from Sigma Chemical Co. (St Louis, MO, USA). 
Table 1 Changes ( \pm S.E.M.) of blood glucose, body weight, food consumption, kidney weight, UAE and glomerular volume measurements in the three groups of rats after 14 days

\begin{tabular}{|c|c|c|c|}
\hline & Control non-diabetic rats & Placebo-treated diabetic rats & $\begin{array}{l}\text { Anti-TGF- } \beta_{2} \text { IgG4-treated } \\
\text { diabetic rats }\end{array}$ \\
\hline Blood glucose $(\mathrm{mM})$ & $5 \cdot 7 \pm 0 \cdot 4$ & $27 \cdot 6 \pm 1 \cdot 2^{*}$ & $24 \cdot 3 \pm 1 \cdot 5^{\dagger}$ \\
\hline Body weight (g) & $221 \cdot 7 \pm 5 \cdot 2$ & $217 \cdot 2 \pm 4 \cdot 3$ & $206 \cdot 3 \pm 4 \cdot 1$ \\
\hline Food consumption (g/24 h) & $18 \pm 2$ & $34 \pm 3^{*}$ & $33 \pm 3^{\dagger}$ \\
\hline Kidney weight $(\mathrm{mg})$ & $705 \pm 5 \cdot 2$ & $897 \pm 4 \cdot 3^{*}$ & $850 \pm 7 \cdot 6^{\dagger}$ \\
\hline $\mathrm{UAE}(\mu \mathrm{g} / 24 \mathrm{~h})$ & $54 \cdot 0 \pm 27 \cdot 5$ & $153 \pm 20 \cdot 8^{*}$ & $124 \pm 16 \cdot 4^{\dagger}$ \\
\hline Glomerular volume $\left(10^{5} \mu \mathrm{m}^{3}\right)$ & $4 \cdot 77 \pm 0 \cdot 68$ & $5 \cdot 64 \pm 0 \cdot 76$ & $5 \cdot 67 \pm 0 \cdot 82$ \\
\hline
\end{tabular}

${ }^{*} P<0 \cdot 05$, non-diabetic rats compared with placebo-treated diabetic rats; ${ }^{\dagger} P<0 \cdot 05$, non-diabetic rats compared with anti-TGF- $\beta 2$ IgG4-treated diabetic rats.

\section{Western blotting}

Western blots were performed on kidney cortex from at least three animals from each group and repeated three times. One hundred micrograms of protein extracted from kidney cortex, and measured by the Bradford procedure detailed elsewhere (Hill et al. 2000), were loaded in each lane of the gel. A $12 \%$ polyacrylamide gel was run and blotted onto polyvinylidene difluoride membrane (BioRad, Hemel Hempstead, UK). The membrane was then incubated overnight with the primary antibody and further incubated with a horseradish peroxidase-labelled secondary antibody and then detected using enhanced chemiluminescence (ECL; Amersham International, Amersham, Bucks, UK). The detailed method for protein extraction, protein quantification and Western blotting was previously described (Hill et al. 2000).

\section{Glomerular volume measurements}

A $2 \mathrm{~mm}$ thick horizontally cut slice from the middle of the right kidney (containing papilla) was fixed in a $4 \%$ paraformaldehyde and embedded in Technovit (Heraeus Kulzer, Wehrheim, Germany). Two-micron thick sections were cut on a rotation microtome and stained with phosphotungsten acid and haematoxylin. The mean glomerular tuft volume $\left(\mathrm{V}_{\mathrm{G}}\right)$ was determined from the mean glomerular cross-sectional area $\left(\mathrm{A}_{\mathrm{G}}\right)$ by light microscopy as previously described (Weibel 1979, Pagtalunan et al. 1995). Profile areas were traced using a computer-assisted morphometric unit (Image Tool; University of Texas Health Science Centre, San Antonio, TX, USA). $A_{G}$ was determined as the average area of a total of 40-80 glomeruli (tuft omitting the proximal tubular tissue within the Bowman's capsule) and $\mathrm{V}_{\mathrm{G}}$ calculated as:

$V_{G}=\beta / k \times\left(A_{G}\right)^{3 / 2}$, where $\beta=1.38$ is the shape coefficient for spheres (the idealised shape of glomeruli) and $k+1 \cdot 1$ is a size distribution coefficient (Weibel 1979, Pagtalunan et al. 1995)

\section{Densitometric and statistical analysis}

Autoradiographs were scanned into a Macintosh computer and subjected to densitometric analysis using Deskscan
II software (Hewlett-Packard, Bracknell, Berks, UK). Densitometric analysis of collagen-I C-propeptide bands in each sample in the Western blots was carried out using NIH image 1.55f software (NIH Shareware; National Institutes of Health, Bethesda, MA, USA). One-way ANOVA was performed on the densitometry results obtained to find which increases were statistically significant when compared with controls.

\section{Results}

\section{Metabolic parameters and body weight}

Over the 14 day experiment the placebo/antagonisttreated diabetic rats remained hyperglycaemic with blood glucose levels around $25 \mathrm{mM}$ (Table 1). The body weight measurements showed both diabetic groups had growth retardation and hyperphagia when compared with non-diabetic rats (Table 1$)$.

Changes in kidney weight, glomerular volume measurements and $U A E$

The TGF- $\beta 2$ antibody, CAT-152, suppressed the increase in both kidney weight and $24 \mathrm{~h}$ UAE seen after 14 days in diabetic animals, although not to control levels (Table 1). The small changes in glomerular volume between control and diabetic rats did not reach statistical significance (Table 1).

\section{Changes in procollagen-I C-propeptide}

Western blotting was performed on protein homogenised from rat kidney cortex (Fig. 1A). Immunoreactivity of procollagen-I C-propeptide increased approximately 3 -fold from non-diabetic control levels to diabetic day 14 $(P<0 \cdot 05$, when diabetic rats were compared with nondiabetic control rats). This increase was attenuated by treatment of diabetics for 14 days with TGF- $\beta 2$ (Fig. 1B), so that at 14 days the levels were not significantly different from those in non-diabetic controls. 
A

$32 \mathrm{kDa}$

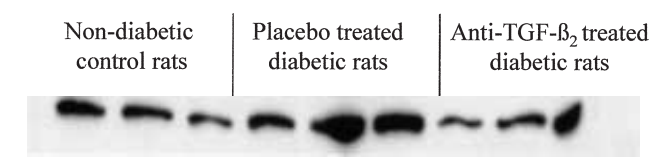

B

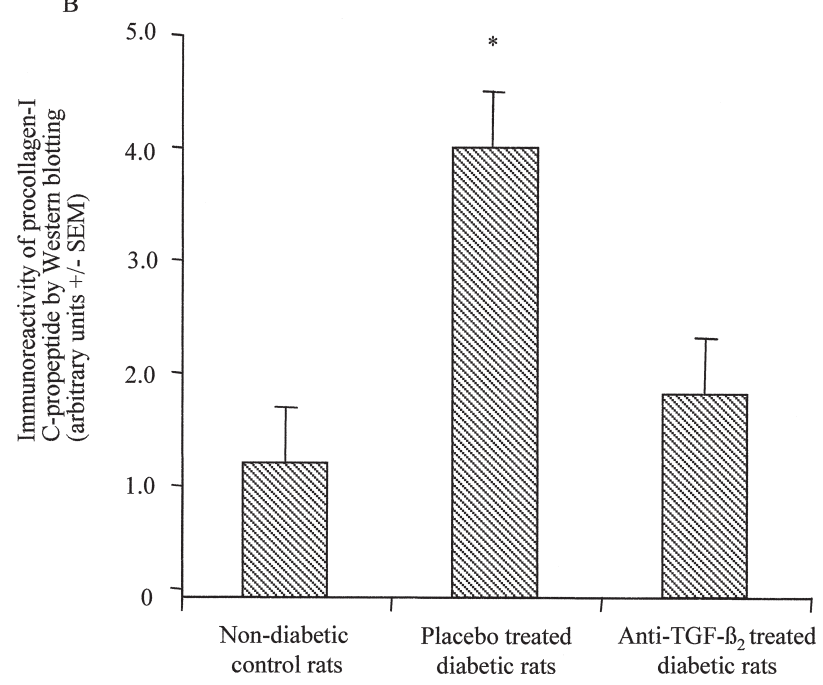

Figure 1 Western blotting data for procollagen-I C-propeptide at termination of study (day 14). (A) Photograph of a representative autoradiograph of a Western blot for procollagen-I C-propeptide in rat kidney cortex of control non-diabetic rats, diabetic rats treated with placebo and diabetic rats treated with the TGF- $\beta 2$ neutralising antibody CAT-152. (B) Graph of densitometry of bands from three Western blots performed. All densitometry in arbitrary units \pm S.E.M.) ${ }^{*} P<0 \cdot 05$, diabetic rats compared with non-diabetic rats.

\section{Discussion}

Overproduction of elements of the TGF- $\beta$ axis is suggested to be key to fibrosis induction within the diabetic kidney and in other fibrotic disease models. Many investigators have attempted to inactivate all or parts of the TGF- $\beta$ axis to prevent fibrosis. For example, Border et al. $(1990,1992)$ blocked the TGF- $\beta 1$ isoform with some success to suppress extracellular matrix production in glomerulonephritis. Others have used a pan-specific antiTGF- $\beta$ antibody to block the activity of all three isoforms and have succeeded in reducing extracellular matrix production in the diabetic kidney (Sharma et al. 1996). Still others have used decorin, a naturally occurring antagonist of all TGF- $\beta$ isoforms, to limit fibrosis in glomerulopathy (Isaka et al. 1996, 1997).

Previously, we have shown by immunocytochemistry and Western blotting that TGF- $\beta 2$ was the predominantly responsive TGF- $\beta$ isoform in the glomeruli of the kidney cortex in STZ-induced diabetic rats between days 3 and 14 of diabetes (Hill et al. 2000). Therefore, we speculated that application of a neutralising antibody specific for the TGF- $\beta 2$ isoform may reduce the amount of fibrosis occurring within the diabetic kidney, and thereby improve early signs of decreasing kidney function.

Like others (El Nehas 1995, Park et al. 1997), we have characterised fibrosis in the kidney by Western blotting for the procollagen-I C-propeptide. The collagen propeptides are necessary for correct folding of the collagen protein. Nand C-terminal propeptides are removed by amino and carboxyl procollagen peptidases, and this occurs prior to collagen-I being laid down in the extracellular matrix. Hence, the presence of C-propeptide is a marker for the rate at which collagen-I is being laid down in the matrix and is, therefore, an adequate indication of when the diabetic kidney initiates fibrosis and when initiation of glomerular scarring is taking place. An antibody against procollagen-I C-propeptide allowed us to examine by Western blotting the rate of collagen-I accumulation during disease induction in the STZ diabetic rat. Clearly, measuring the $\mathrm{C}$-propeptide does not quantify the total amount of collagen-I in the kidney, only the periods of most turnover of procollagen-I to mature collagen-I, i.e. periods of active fibrogenesis. Previous work by us showed that procollagen-I C-propeptide immunoreactivity increased in the kidney cortex from control levels to a peak at day 14 of experimental diabetes and, thereafter, it decreased back to control levels (Hill et al. 2000). This indicated that the period of most active fibrogenesis in the diabetic kidney occurs in the first 14 days of diabetes. Importantly, in the experiment described herein, the levels of procollagen-I C-propeptide were significantly suppressed in the kidney cortices of TGF- $\beta 2$ antibodytreated diabetic rats when compared with levels in the placebo-treated diabetic rats. The effect was marked so that, by 14 days of experimental diabetes, the levels were not significantly different from those in non-diabetic controls. This observation indicates that systemic delivery of the TGF- $\beta 2$ antagonist, CAT-152, during the acute stages of diabetic nephropathy was effective in reducing the rate of kidney fibrogenesis.

In the experiment described here, kidney weights and UAE were consistently reduced at 14 days when the anti-TGF- $\beta 2$ antibody-treated diabetic rats were compared with the untreated diabetic rats although, at this time point, not to levels seen in non-diabetic controls. The incomplete protective effect observed with the antiTGF- $\beta 2$ antibody treatment is reminiscent of the results of previous work with other TGF- $\beta$ antibodies which have never totally prevented fibrosis nor fully corrected kidney morphology and function (Border et al. 1992, Isaka et al. 1996, Sharma et al. 1996). Therefore, it might be concluded that TGF- $\beta 2$, like the other TGF- $\beta$ isoforms, may not be alone in initiating fibrosis and compromising kidney function, although the results indicate that it does play an important contributory role. It could be that, when the levels of TGF- $\beta 2$ are reduced, the other isoforms of TGF- $\beta$ compensate. Furthermore, the renoprotective effects of CAT-152 may become more marked at 
longer time periods of treatment and optimisation of the antagonist delivery strategy may improve its efficacy.

In summary, our data demonstrate that specifically neutralising the activity of the TGF- $\beta 2$ isoform with a recombinant human monoclonal antibody, CAT-152, during the first 14 days of diabetes has a renoprotective effect as it attenuated the synthesis of collagen-I, the rise in kidney weight and the production of urinary albumin. The results confirm the importance of TGF- $\beta$ s as fibrogenic factors in the diabetic kidney and indicate the potential usefulness of TGF- $\beta$ antagonists such as CAT152 as renoprotective agents.

\section{Acknowledgements}

This study was supported by grants from the Danish Medical Research Council (No. 9700592), the Danish Diabetes Association, the Danish Kidney Foundation, the Ruth König Petersen Foundation, the Novo Foundation, the Aage Louis-Hansen Memorial Foundation, the Eva and Henry Fraenkels Memorial Foundation, the Nordic Insulin Foundation and the Aarhus University-Novo Nordisk Centre for Research in Growth and Regeneration (No. 9600822) and the Department of Medicine, University of Birmingham, UK. We are grateful to Mrs Karen Mathiassen, Kirsten Nyborg and Ninna Rosenqvist for excellent technical assistance.

\section{References}

Borch-Johnsen K \& Kreiner S 1987 Proteinuria: value as predictor of cardiovascular mortality in insulin-dependent diabetes mellitus. British Medical Journal 294 1615-1654.

Border WA, Okuda S, Languino LR, Sporn MB \& Reuslahti E 1990 Suppression of experimental glomerulonephritis by antiserum against transforming growth factor- $\beta 1$. Nature 346 371-374.

Border WA, Yamamoto T, Harper JR, Yamoguchi Y, Pierschacher MD \& Reuslahti E 1992 Natural inhibition of TGF- $\beta$ protects against scarring in experimental kidney disease. Nature $\mathbf{3 6 0}$ 361-364.

Deckert T, Poulsen JE \& Larsfin M 1978 Prognosis of diabetics with diabetes onset before age of thirty one. Diabeteologia 14 363-370.

El Nahas AM 1995 Pathways to renal fibrosis. Experimental Nephrology $371-75$.

Flyvbjerg A 1997 Role of growth hormone, insulin-like growth factors (IGFs) and IGF-binding proteins in the renal complications of diabetes. Kidney International 52 S12-S19.

Flyvbjerg A, Marshall SM, Frystyk J, Hansen KW, Harris AG \& Orskov H 1992 Octreotide administration in diabetic rats: effects on renal hypertrophy and urinary albumin excretion. Kidney International 41 805-812.

Flyvbjerg A, Hill C \& Logan A 1999 Pathophysiological role of growth factors in diabetic kidney disease: focus on innovative therapy. Trends in Endocrine Metabolism 10 267-272.

Hill C, Flyvbjerg A, Gronbaek H, Petrik J, Hill DJ, Thomas CR, Sheppard MC \& Logan A 2000 The expression of transforming growth factor beta (TGF- $\beta$ ) isoforms and their receptors in acute and chronic experimental diabetic nephropathy. Endocrinology 141 1196-1208.
Isaka Y, Brees DK, Ikegaya K, Kaneda Y, Imai E, Noble NA \& Border WA 1996 Gene therapy by skeletal muscle expression of decorin prevents fibrotic disease in rat kidney. Nature Medicine $\mathbf{2}$ 418-423.

Isaka Y, Akagi Y, Ando Y \& Imai E 1997 Application of gene therapy to diabetic nephropathy. Kidney International 52 S100-S103.

Jackson H, Bacon L, Pedley B, Derbyshire E, Field A, Osbourn J \& Allen D 1998 Antigen specificity and tumour targeting efficiency of a human carcinoembryonic antigen specific $\mathrm{scFv}$ and affinity matured derivatives. British Journal of Cancer 78 181-188.

Mogensen CE \& Christensen CK 1984 Predicting diabetic nephropathy in insulin dependent patients. New England Journal of Medicine 311 89-93.

Osterby R, Lundbaek K, Olsen TS \& Orskov H 1967 Kidney lesions in rats with severe long term alloxan diabetes. Laboratory Investigation 17 675-692.

Pagtalunan ME, Rasch R, Rennke HG \& Meyer TW 1995 Morphometric analysis of effects of angiotensin II on glomerular structure in rats. American Journal of Physiology 268 F82-F88.

Pankewycz OG, Guan JX, Kline-Bolton W, Gomez A \& Benedict JF 1994 Renal TGF- $\beta$ regulation in spontaneously diabetic NOD mice with correlations in mesangial cells. Kidney International 46 748-758.

Park I-S, Kiyomoto H, Abboud SL \& Abboud HA 1997 Expression of transforming growth factor- $\beta$ and type IV collagen in early streptozotocin-induced diabetes. Diabetes 46 473-480.

Rocco MV, Chen Y, Goldfarb S \& Ziyadeh FN 1992 Elevated glucose stimulates TGF- $\beta$ gene expression and bioactivity in proximal tubules. Kidney International 41 107-114.

Seyer-Hansen K 1976 Renal hypertrophy in streptozotocin diabetic rats. Clinical Science and Molecular Medicine 51 551-555.

Shankland SJ \& Scholey JW 1994 Expression of transforming growth factor $\beta 1$ during diabetic renal hypertrophy. Kidney International 46 430-442.

Sharma K \& Ziyadeh FN 1994 Renal hypertrophy is associated with upregulation of TGF- $\beta 1$ gene expression in diabetic BB rat and NOD mouse. American Journal of Physiology 67 F1094-F1101.

Sharma K, Jin Y, Guo J \& Ziyadeh N 1996 Neutralization of TGF- $\beta$ by anti TGF- $\beta$ antibody attenuates kidney hypertrophy and the enhanced extracellular matrix gene expression in STZ induced diabetic mice. Diabetes 45 522-530.

Thompson JE, Vaughan TJ, Williams AJ, Wilton J, Johnson KS, Bacon L, Green JA, Field R, Ruddock S, Martins M, Pope AR, Tempest PR \& Jackson RH 1999 A fully human antibody neutralising biologically active human TGF $\beta 2$ for use in therapy. Journal of Immunological Methods 227 17-20.

Viberty GC, Hill RD, Jarrett RJ, Argyropoulos A, Mahmud U \& Keen H 1982 Microalbuminuria as a predictor of clinical nephropathy in insulin-dependent diabetes mellitus. Lancet i (8287) 1430-1432.

Weibel ER 1979 Stereological methods: volume I, practical methods for Biological Morphometry. London: Academic Press.

Ziyadeh FN, Chen Y, Davila A \& Goldfarb S 1992 Self limited stimulation of mesangial cell growth in high glucose: autocrine activation of TGF- $\beta$ reduces proliferation but increases mesangial matrix. Kidney International 42 647-656.

Ziyadeh FN, Hoffman BB, Han DC, Iglesias-de al Cruz MC, Won Hong S, Isono M, Chen S, McGowan TA \& Sharma K 2000 Long term prevention of renal insufficiency, excess matrix gene expression, and glomerular mesangial matrix expansion by treatment with monoclonal anti-transforming growth factor- $\beta$ antibody in $d b / d b$ diabetic mice. PNAS 97 8015-8020.

Received in final form 21 February 2001 Accepted 30 May 2001 